\title{
The Five Continents of Theatre. Facts and Legends about the Material Culture of the Actor
}

\section{Eugenio Barba and Nicola Savarese}

Brill: 2019, 411 p.

\section{ANNELIS KUHLMANN, Aarhus University}

Professor Emeritus, Nicola Savarese and theatre director, Eugenio Barba have written and compiled a large historiographical theatre collection of data with focus on the material culture of the actor based on facts and legends. The book is weighty, both metaphorically and materially. The Five Continents of Theatre (2019) was first published in Italian, (2017), then in Rumanian (2018), now in English (2019), and in 2020 the book will appear in Spanish (Artezblai, Madrid) as well as in French (Seconde Époque, Paris).

The preface to the book is by Associate Professor Tatiana Chemi, Aalborg University (Denmark), who also is co-editor of the series Arts, Creativities, and Learning Environments in Global Perspectives at Brill. She identifies the book as belonging to the genre of an actor's grimoire, in Latin originally meaning obscure information, but here refers to the 'magic' in the message, in the imaginary and creative witchcraft, which at a certain level of the profession, in a sense supports the actor's craft.

Previously, Barba and Savarese edited The Secret Art of the Performer (2005), which similarly, has been translated into many languages and reprinted in English several times. The artistic and scholarly research in their new book is also a collaborative practice which has its own genuine trajectory of results. 
Their approach is paradoxical. It is archival, meaning that the book makes us rethink the big questions about temporality in theatre: what remains of and what presupposes the ephemeral art of the actor, which traditionally has been understood as an act of disappearance? At the same time, the book also underscores the preciousness of what can be retold and transformed from the actor's craft, its legends and their relationship to scientific narratives. This multidisciplinary way of thinking highlights the importance of drawing attention to the different sorts of contexts that surround the actor, and to which the actor responds.

\section{BEHIND THE BOOK}

The title of the book refers to global exploration into the culture of the actor. This approach resonates with the interest displayed by Eugenio Barba since the early days of Odin Teatret; namely that of the actor's scenic behaviour, an interest which after some time found a collaboration with the late Odissi dancer, Sanjukta Panigrahi, together with whom he founded The International School of Theatre Anthropology (ISTA) in 1978. ISTA suggested that the different cultural and scenic behaviours of actors were not only seen as traceable across performance arenas, but were also conceived as being negotiable, as the experiences with barter had proved from the early 1970s.

Savarese's experience at the University of Rome, teaching ancient European theatre history, and from research residencies in Japan and other Far East countries, provides for a contribution that indicates his archival interest in the sources behind performance forms.

\section{RESEARCH QUESTIONS IN 1400 ILLUSTRATIONS}

The interesting aspect of The Five Continents of Theatre is a powerful alternative act of mnemonics in the field of theatre history. In my view, this book should be seen as complementary to most conventional theatre historiographies available on the market at the moment. Let us hope for an e-book version.

The Five Continents of Theatre offers a double methodological research question, in particular that of engaging with the philosophical thinking about facts and legends in relationship to the actor. This is where the co-authorship between Savarese and Barba demonstrates its strength.

Reading The Five Continents of Theatre leaves an impression of changing spaces in theatre landscapes, and provides a web of relationships drawing continuous lines to legends, with an overwhelming complexity of configurations. No less than 1400 illustrations, referring to the culture of actors, visualize the facts and evoke the imagination of the reader. It is very rare, if ever, that we witness such a surprising quantity of valuable and astonishing illustrations accumulated in one publication. In their own sense, these illustrations represent a particular way of looking and researching in the theatre, and they reveal an engaging comprehension of the imaginative as a cognitive and sensorial skill in the actor's craft. The organisation of the illustrations bear witness to the theatre director's archival regard for the scope of theatre traditions worldwide, each with their respective material culture of the actor. As a result, the scholar looks through images, composing them in a stimulating way and leaving the readers with enriched imageries in their 
perception of the book's mnemonics. Thanks to the publisher at BRILL, the price of this worthy book makes it accessible for students and theatre practitioners!

The impact of research in theatre anthropology and the practice of barter seem to be situated in-between the lines of The Five Continents of Theatre as part of the experience it offers, and within which the culture of the actor is present throughout the book. The intercultural dimension of the experience of artistic research, the result of which can be seen in this publication, has over the years, been critically discussed by researchers with mainly postcolonial perspectives. It might be expected that this critique is repeated in the case of the new book, especially since both African and Afro-American performance cultures are absent as are Australian or aboriginal dances or cultural performances. This may be because the African and the Australian continents have never occupied much space in Savarese and Barba's previous research. For Barba, this is also probably because his theatre ensemble at Odin Teatret was never really successful in touring to these continents. Thus, Barba's and Savarese's common interest has been oriented towards the theatre and acting legacy of Eastern Europe, such as in Russia, and to the far East in countries such as Indonesia, Japan, China and Bali. After twenty years of research, The Five Continents of Theatre has reached its audience, and we might add that this book reflects the multiplicity of the theatre journeys that both authors have undertaken throughout their entire professional careers. A further Twenty One writers have collaborated with shorter texts in this book.

A major and particularly interesting scientific aspect of The Five Continents of Theatre is that the mapping not only covers a geographical surface of territories, where the impact of the actor's culture has been the most intense, but also digs below the surface, and discovers a myriad of astonishing and beautiful relationships between the traditions. Reading this book, one gets the impression of a multitude of theatres around the world. This diversity aspect is organised in such a way, that the imaginative, 'pop-up' effect, influenced by the high density of images, becomes almost a body-mind technique in itself. The mappings of so many details leave the impression of a global theatre archive, which, here, has in a sense been curated as a 're-archiving'. The message to the reader comprises an archive of living forms, which themselves see and acknowledge a physicality in the actor's culture. Whilst drawing attention to the physical materiality of the actor's culture, the reader becomes aware furthermore of what, conventionally, is not seen as a material for the actor. This making of the invisible visible contains its own magical logic. 